\title{
Monitoring of the ionosphere TEC variations during the 17th August 1999 Izmit earthquake using GPS data
}

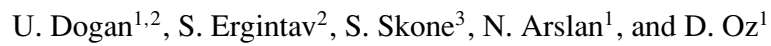 \\ ${ }^{1}$ Department of Geomatic Engineering, Yildiz Technical University, İstanbul, Turkey \\ ${ }^{2}$ TUBITAK MRC Earth and Marine Sciences Institute, Gebze, Kocaeli, Turkey \\ ${ }^{3}$ Department of Geomatics Engineering, University of Calgary, Calgary, Canada
}

(Received February 2, 2011; Revised July 14, 2011; Accepted August 1, 2011; Online published February 21, 2012)

\begin{abstract}
In this paper, we aim to determine a snapshot of previously unstudied ionospheric variations which were recorded in a two-week interval before and after a large earthquake of $M 7.6$ occurred on 17 August, 1999, in the Marmara region of Turkey. We detected ionospheric perturbations before the earthquake occurred using Global Positioning System (GPS) data received from the Marmara Continuous GPS Network (MAGNET). Pre-seismic ionospheric total electron content (TEC) anomalies were observed three days before the earthquake at sets of stations near the earthquake location, while post-seismic traveling ionospheric disturbances could not be detected. The ionospheric variability had a negative sign with an enhancement of about $8-10$ TECU ( 1 TECU $=10^{16}$ electrons $/ \mathrm{m}^{2}$ ) relative to the non-distributed state of the ionosphere. The results show that this method will be a useful addition to the already-available continuous monitoring techniques in the region.
\end{abstract}

Key words: Izmit earthquake, GPS, ionosphere, TEC, MAGNET.

\section{Introduction}

GPS measurements have provided a potential tool for detecting ionospheric perturbations related to earthquakes, since GPS data can be used to measure the ionospheric total electron content (TEC). The TEC is the integrated electron density and is a useful parameter for ionospheric studies. Intensive studies of seismo-ionospheric effects, together with traditional methods of geophysical forecasting, are conducted for the development of various methods of the earthquake forecasting (e.g., Zakharenkova et al., 2007). The main dif culty in identifying earthquake effects is due to the day-to-day variability of the ionosphere. The amplitude of seismo-ionospheric effects is comparable to these changes. The occurrence of these effects depends on the magnitude of earthquake, local time and geophysical locations (Krankowski et al., 2006).

Variations of the ionospheric electron density arising from geophysical events, such as earthquakes and volcanic eruptions, have been investigated since the great Alaskan earthquake of 1964 (Davis and Baker, 1965). In recent years, many studies have been undertaken to identify precursors of earthquakes, as well as to understand the physical mechanisms of seismo-ionospheric coupling with the ionosphere as one of the sources of ionospheric variability (Pulinets, 1998). Also, scientists have found an apparent reduction in GPS TEC a few days prior to some strong earthquakes (e.g., Liu et al., 2001, 2004, 2011; Saroso et al., 2008; Le et al., 2011). Liu et al. (2004) exam-

Copyright (C) The Society of Geomagnetism and Earth, Planetary and Space Sciences (SGEPSS); The Seismological Society of Japan; The Volcanological Society of Japan; The Geodetic Society of Japan; The Japanese Society for Planetary Sciences; TERRAPUB.

doi:10.5047/eps.2011.07.020 ined pre-earthquake ionospheric anomalies by TEC derived from a ground-based GPS receiver. They reported that pre-earthquake ionospheric anomalies appeared during 1822 LT within 5 days prior to the occurrence of 16 of the $20 M \geq 6.0$ earthquakes in the Taiwan area from September 1999 to December 2002. Also, Liu et al. (2011) reported that the temporal TEC variation over the epicenter indicated a pre-seismic anomaly as being a signi cant enhancement of the ionospheric TEC 1 day before the 2010 M 7 Haiti Earthquake.

Le et al. (2011) studied statistically pre-earthquake ionospheric anomalies by using TEC data from the global ionosphere map (GIM) for a total of $736 M \geq 6.0$ earthquakes which occurred in the global area in the period 2002-2010. The results indicated that the anomalous behavior of the TEC, within just a few days before the earthquakes, is related to the forthcoming earthquakes with a high probability.

Pulinets et al. (2003) have summarized the results of more than ten years spent studying the variations in the ionosphere over seismically-active regions several days, or hours, before strong earthquakes. They also reported the main properties of TEC variations associated with earthquake precursors.

Pulinets et al. (2004) investigated the variability of electron concentration in the ionosphere, measured by groundbased ionosondes and GPS receivers around the time of strong earthquakes. It was determined that, several days before the seismic shock, the level of this variability increased at the station closest to the epicenter.

Afraimovich et al. (2004) showed that the observed TEC variations seem to have been related to the local time and by fairly moderate geomagnetic activity, instead of being 


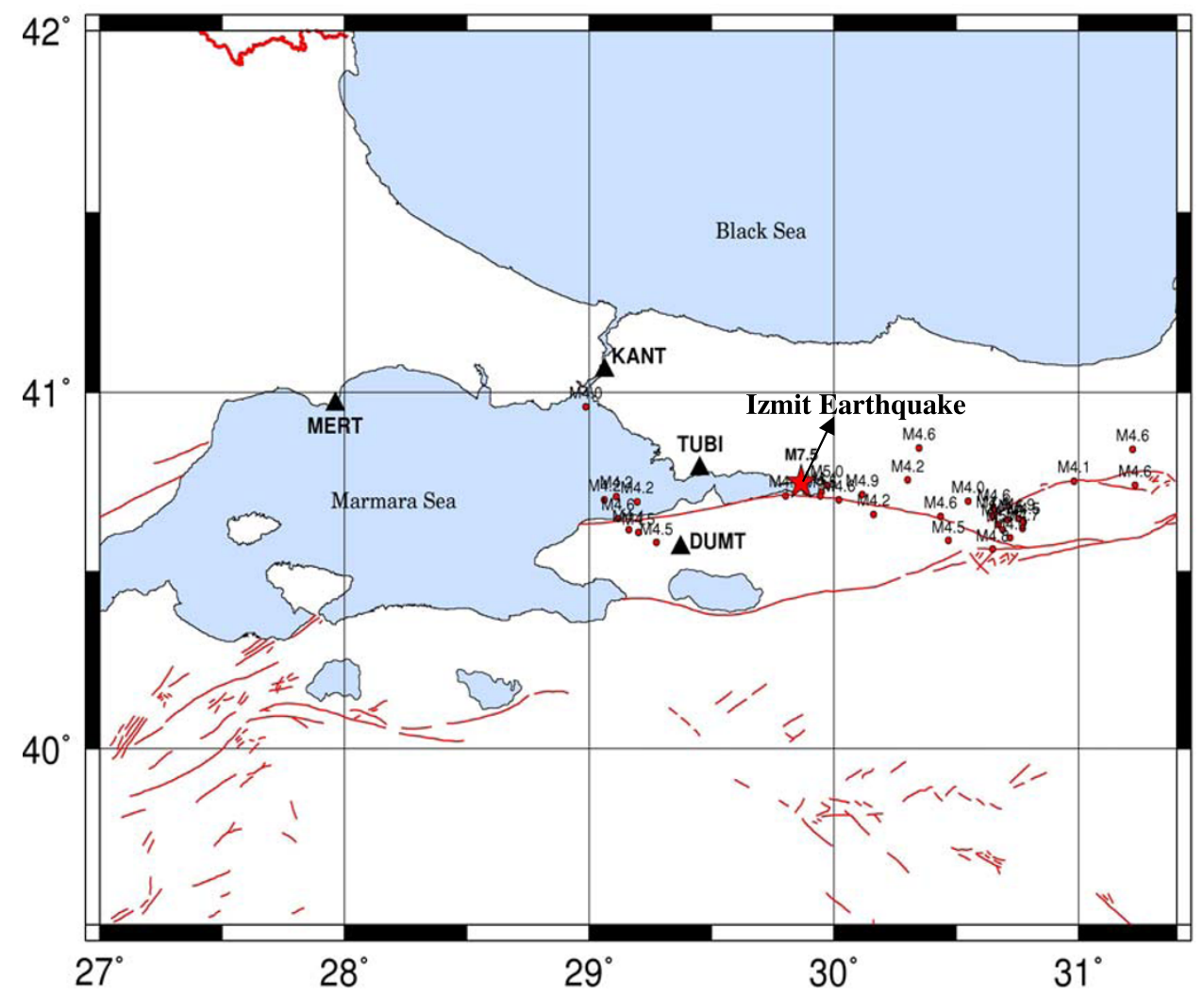

Fig. 1. The locations of the GPS stations and the earthquakes in the Marmara Region in 1999. The triangle denote the GPS stations, the circles denote the earthquakes, and the star shows the Izmit earthquake.

associated with any expected processes that usually precede earthquakes.

Afraimovich et al. (2008) compared local TEC changes over an area of an earthquake's epicenter with global TEC variations, and with local TEC over a seismically-quiet "check"-region. They also analyzed the effect of TEC day-to-day changes before strong earthquakes and indicated that, in some cases, this effect might be a reflection of global changes of the ionization caused by the 27-day variations, as well as other fast changes, due to solar and geomagnetic activity changes.

Dautermann et al. (2007) investigated ionosphere electron content variations preceding the San Simeon (22 December, 2003, $M=6.6$ ) and Parkfield (29 September, 2004, $M=6.0$ ) earthquakes in Southern California, using GPS TEC measurements performed by the South California Integrated GPS Network sites. They found anomalous TEC signals but no statistically-significant correlation in time, or in space, between these TEC anomalies and the occurrence of the earthquakes in Southern California.

In this study, an analysis of the GPS TEC variations during the 17th August, 1999, Izmit earthquake is presented. This large earthquake occurred in the Eastern Marmara Sea region and caused considerable loss of life and damage in the region. The August 17th earthquake's epicenter was located at $40.80^{\circ} \mathrm{N}$ latitude and $30^{\circ} \mathrm{E}$ longitude. The earthquake had a depth of around $10 \mathrm{~km}$ and lasted 45 seconds and its magnitude $\left(M_{\mathrm{w}}\right)$ was 7.5.

A better understanding of the most active structural framework of the Marmara Sea region, particularly the in- fluence of the North Anatolian Fault, an ideal natural laboratory not only for us but also for all scientific people in the world, is very important as the area is in one of the most highly-populated regions of Turkey (and of the Eastern Mediterranean). Therefore, earthquake predictionrelated studies and hazard estimation have first priority to prepare public and decision-makers and to reduce the vital losses. Following the last devastating Izmit and Duzce earthquakes (Turkey) in 1999, different research groups have concentrated their efforts in this region, using multidisciplinary monitoring techniques that include seismology, borehole tilt/strain measurements, Global Positioning System (GPS)/interferometric synthetic aperture radar (InSAR), and the geochemistry of gas (e.g. radon) and water emanating from major fracture zones. However, monitoring these efforts have not included ionospheric TEC variations with GPS. Of course after the 1999 earthquakes, some studies were carried out by the International GNSS Service (IGS) to discuss the rough ionospheric GPS TEC anomalies from far sites.

The goal of this paper is not to explain the possible connection between ionospheric anomalies and earthquakes, since this is still under debate in the scientific community. Our first goal is to demonstrate the contribution of near field continuously-operating GPS sites in the epicenter rupture zone of the 17 August, 1999, earthquake, in order to show the capabilities of this technique, as a pre-earthquake method, in the region. Secondly, we show new results from the unpublished data and increase the reliability of the results of the far field sites in the previous studies. 
Table 1. GPS stations and time intervals of the epochs.

\begin{tabular}{|c|c|c|c|c|c|c|c|c|c|c|c|c|c|c|c|c|c|}
\hline \multirow[t]{2}{*}{ Stations } & \multirow{2}{*}{$\begin{array}{l}\text { Latitude } \\
\text { (degree) }\end{array}$} & \multirow{2}{*}{$\begin{array}{c}\text { Longitude } \\
\text { (degree) }\end{array}$} & \multicolumn{15}{|c|}{ GPS Days for August 1999} \\
\hline & & & 222 & 223 & 224 & 225 & 226 & 227 & 228 & 229 & 230 & 231 & 232 & 233 & 234 & 235 & 236 \\
\hline DUMT & 40.5655 & 29.3719 & - & - & $*$ & $*$ & $*$ & - & $*$ & $*$ & $*$ & $*$ & $*$ & $*$ & $*$ & $*$ & $*$ \\
\hline KANT & 41.0608 & 29.0614 & $*$ & $*$ & $*$ & * & * & * & * & $*$ & * & * & * & * & * & * & $*$ \\
\hline MERT & 40.9669 & 27.9617 & $*$ & * & $*$ & * & * & * & $*$ & * & * & * & * & * & * & * & $*$ \\
\hline TUBI & 40.7867 & 29.4507 & $*$ & * & $*$ & $*$ & $*$ & $*$ & $*$ & $*$ & $*$ & $*$ & * & $*$ & $*$ & $*$ & $*$ \\
\hline
\end{tabular}

*data available, (-) data not available.

Hence, the purpose of this paper is to study the ionospheric anomalies recorded by GPS TEC around the time of the 17th August Izmit earthquake in the Marmara active seismic zone, and to give a snapshot of the ionospheric variations which occurred during that time. In addition, our data sets may provide useful information concerning ionospheric TEC variations and earthquake prediction.

\section{GPS Data Sets and Processing}

Four continuous GPS stations (TUBI, DUMT, MERT, KANT) of the Marmara Continuous GPS Network (MAGNET), installed by The Scienti c and Technical Research Council of Turkey (TUBITAK), Earth and Marine Sciences Research Institute (EMSRI), were operating before the Izmit earthquake within the coseismic rupture zone. GPS data sets were obtained from this network. MAGNET was established before the 17 August, 1999, Izmit earthquake to measure the deformation associated with strain accumulation along the western NAF system (Ergintav et al., 2002). Figure 1 shows the station distribution of MAGNET during the 17 August, 1999, Izmit earthquake (MAGNET now has 21 stations). The station coordinates and time intervals of the epochs are listed in Table 1. The data consist of daily les collected by Trimble 4000 SSI receivers-all using choke ring antennas, with an observation rate of 30 seconds.

The GPS data were processed following standard procedures, and using the Bernese GPS software Version 4.2 developed by the University of Bern, Switzerland (Hugentobler et al., 2001). In the processing, we used the International GPS Service (IGS) nal precise satellite ephemeris, and earth rotation parameters were obtained from the IGS Central Bureau website. The troposphere zenith delays were estimated for each station at two-hour intervals. The network was minimally constrained by xing the ITRF 2000, epoch 1997.0, coordinates of the ANKR station (located at $39.89^{\circ} \mathrm{N}, 32.76^{\circ} \mathrm{E}$ ) computed by the Scripps Orbit and Permanent Array Center (SOPAC).

\section{Short-term Displacement Rates from GPS Measurements}

GPS data observation periods of 24 hours are sensitive to estimated deformation rates. Therefore, observation epochs of GPS data observation periods of 24 hours collected before (GPS days 222-228) and after (GPS days 229-236) the 17 August, 1999, Izmit earthquake were studied in order to determine crustal deformations in the Marmara region. Time series of each of the station coordinates were computed with respect to the ANKR station. The baseline time series of each of the stations relative to the ANKR station are shown in Fig. 2. To generate the results shown in this gure, daily GPS solutions were minimally constrained by xing the coordinates of the ANKR station, since ANKR was the single far site to the deformation eld of the region in our baseline solutions, and the contributions to the deformation eld were very small.

From the baseline time series for stations relative to ANKR, indicated in Fig. 2, signi cant relative motion has been found in the coseismic time of the 17 August, Izmit, earthquake. The relative coseismic deformations between stations (TUBI and DUMT) located close to the epicenter of the earthquake were dominated by a large about $62.7 \mathrm{~cm}$ and $24.4 \mathrm{~cm}$, respectively. However, the relative deformation rates between stations (KANT and MERT) located to the north of the fault were dominated by a large about $13.3 \mathrm{~cm}$ and $2.2 \mathrm{~cm}$, respectively. The deformation rate increases with time at a decreasing rate following the instantaneous deformation during the earthquake can be expected from the real earth (Dogan et al., 2003).

\section{GPS TEC Data Analysis}

The GPS data are considered before and after the 17 August, 1999, Izmit earthquake to determine the TEC variations in Marmara Region. The GPS TEC has been determined using TECANALYS software which was developed at the Department of Geomatics Engineering, University of Calgary. The software consists of multiple $\mathrm{C}$ programs that process GPS pseudo-range and carrier phase observations to derive estimates of the ionospheric TEC (Skone, 2006).

An absolute estimate of the slant TEC is derived from the code pseudo-ranges as follows:

$$
\mathrm{TEC}=\frac{f_{1}^{2} f_{2}^{2}}{40.3\left(f_{2}^{2}-f_{1}^{2}\right)}\left(P_{1}-P_{2}\right)\left(\mathrm{el} / \mathrm{m}^{2}\right) .
$$

Where TEC denotes the total electron content integrated along a $1-\mathrm{m}^{2}$ column along the signal path $\left(\mathrm{el} / \mathrm{m}^{2}\right), f_{1}=$ 1575.42 MHz and $f_{2}=1227.60 \mathrm{MHz}$ for the case of a dual frequency GPS receiver, $P$ indicates the pseudo-range observable and the TEC is usually expressed in units of TECU $\left(10^{16} \mathrm{el} / \mathrm{m}^{2}\right)$ (Skone, 2001, 2006).

Relative estimates of the slant TEC are derived from the precise phase ranges as follows:

$$
\mathrm{TEC}=\frac{-f_{1}^{2} f_{2}^{2}}{40.3\left(f_{2}^{2}-f_{1}^{2}\right)}\left(\Phi_{1}-\Phi_{2}\right)\left(\mathrm{el} / \mathrm{m}^{2}\right) .
$$

The phase ranges are corrupted by noise and multipath to a much lesser extent than the pseudo-range observations. 

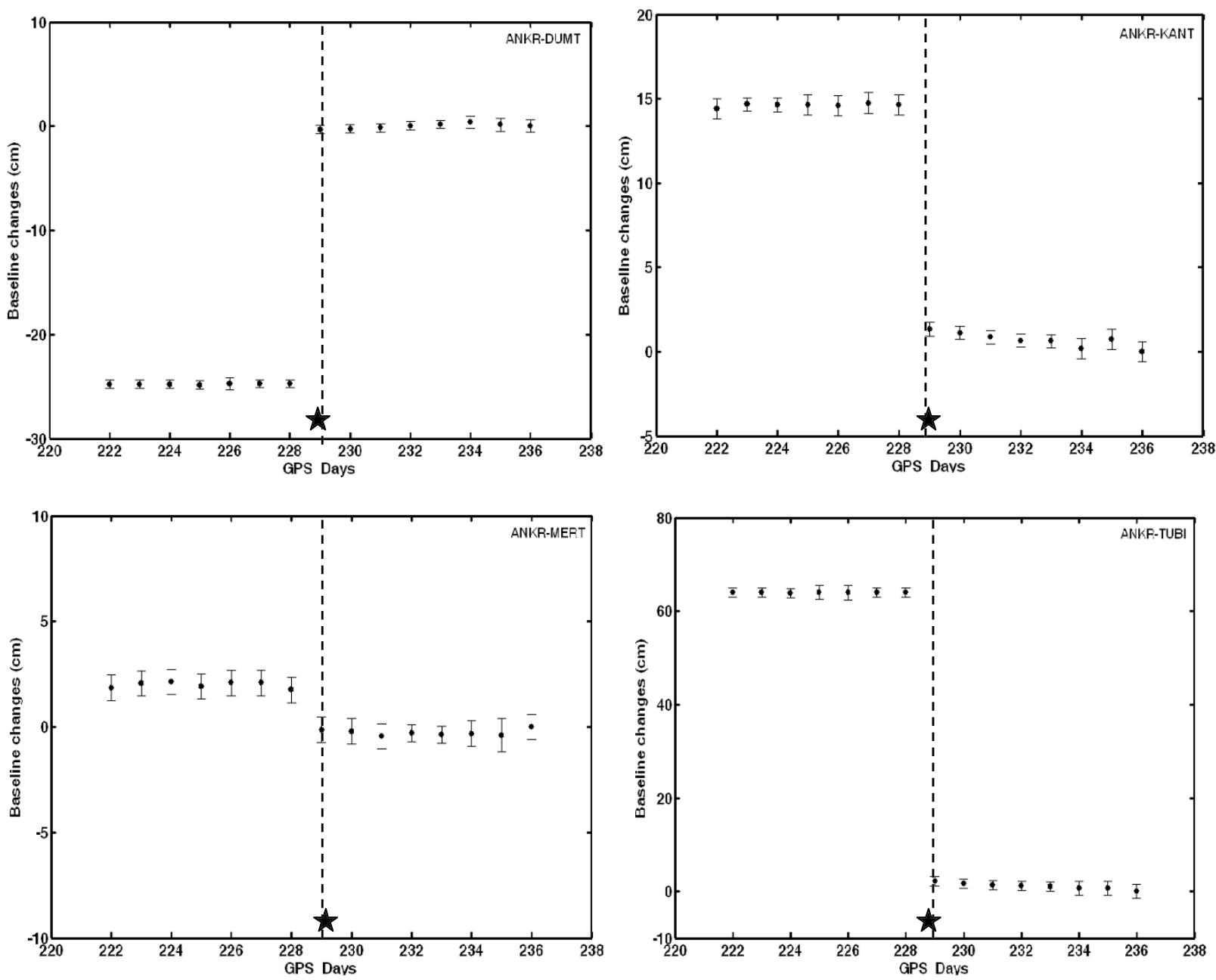

Fig. 2. Baseline timeseries for stations, relative to ANKR. The star and the dashed line denote the earthquake time.

Such TEC estimates have a relative accuracy of better than 0.10 TECU RMS, and can be used to analyze relative spatial and temporal variations in the TEC (Skone, 2001, 2006). The rates are computed from the first differences of the slant TEC, which is derived as follows for a given satellite:

$$
\Delta \mathrm{TEC}_{i, s}=\mathrm{TEC}_{i, s}-\mathrm{TEC}_{i-1, s} .
$$

Where the slant phase TEC is differenced between epochs $i$ and $i-1$ for satellite $s$. In this case, ambiguity terms at epochs $i$ and $i-1$ will cancel, provided that they remain constant over time (i.e. no cycle slips) (Skone, 2006).

The slant TEC value along the satellite-receiver line of sight can be mapped to the vertical in an ionosphere shell by applying an approximate mapping factor. The mapping factor becomes:

$$
M(E)=\left\{1-\left(\frac{R_{\mathrm{E}}}{R_{\mathrm{E}}+h}\right)^{2} \cos ^{2} E\right\}^{1 / 2} .
$$

Where $E$ is the elevation angle of satellite, $h$ is the ionospheric thin shell height and $R_{\mathrm{E}}$ is the radius of the Earth.

The first difference of the vertical TEC (VTEC) is computed as:

$$
\Delta \mathrm{VTEC}_{i, s}=M\left(E_{\mathrm{ave}}\right) \times \Delta \mathrm{TEC}_{i, s} .
$$

Where $E_{\text {ave }}$ is the average elevation angle:

$$
E_{\text {ave }}=\left(E_{i}+E_{i-1}\right) / 2 \text {. }
$$

The rate of change of the vertical TEC is then computed as (Skone, 2006):

$$
\mathrm{VTEC}_{i, s}=\Delta \mathrm{VTEC}_{i, s} /\left(t_{i}-t_{i-1}\right)
$$

It is known that the detection of seismo-ionospheric effects is rather complicated in periods of geomagnetic disturbances. Ionospheric modification caused by geomagnetic storm activity can promote amplification, or weakening, of the manifestation of seismo-ionospheric effects (e.g., Zakharenkova et al., 2007). Figure 3 indicates the variations of geomagnetic-activity indices $\left(K_{\mathrm{p}}\right.$ and $\left.D_{\mathrm{st}}\right)$ for the period of August 10-25 (Days of the Year (DOY) 222-237), 1999. As shown in Fig. 3, the geomagnetic condition was not relatively quiet during the period 10-25 August, 1999, before and after the Izmit earthquake. There was a small geomagnetic storm before the earthquake, when $K_{\mathrm{p}} \geq 5$ and $D_{\text {st }} \geq 20 \mathrm{nT}$. There was an intense geomagnetic storm after the earthquake, when $K_{\mathrm{p}} \geq 5$ and $D_{\mathrm{st}} \geq-60 \mathrm{nT}$.

Figure 4 shows vertical TEC observations from the dualfrequency GPS reference stations KANT, MERT and TUBI of MAGNET. The daily variations indicate that, three days 

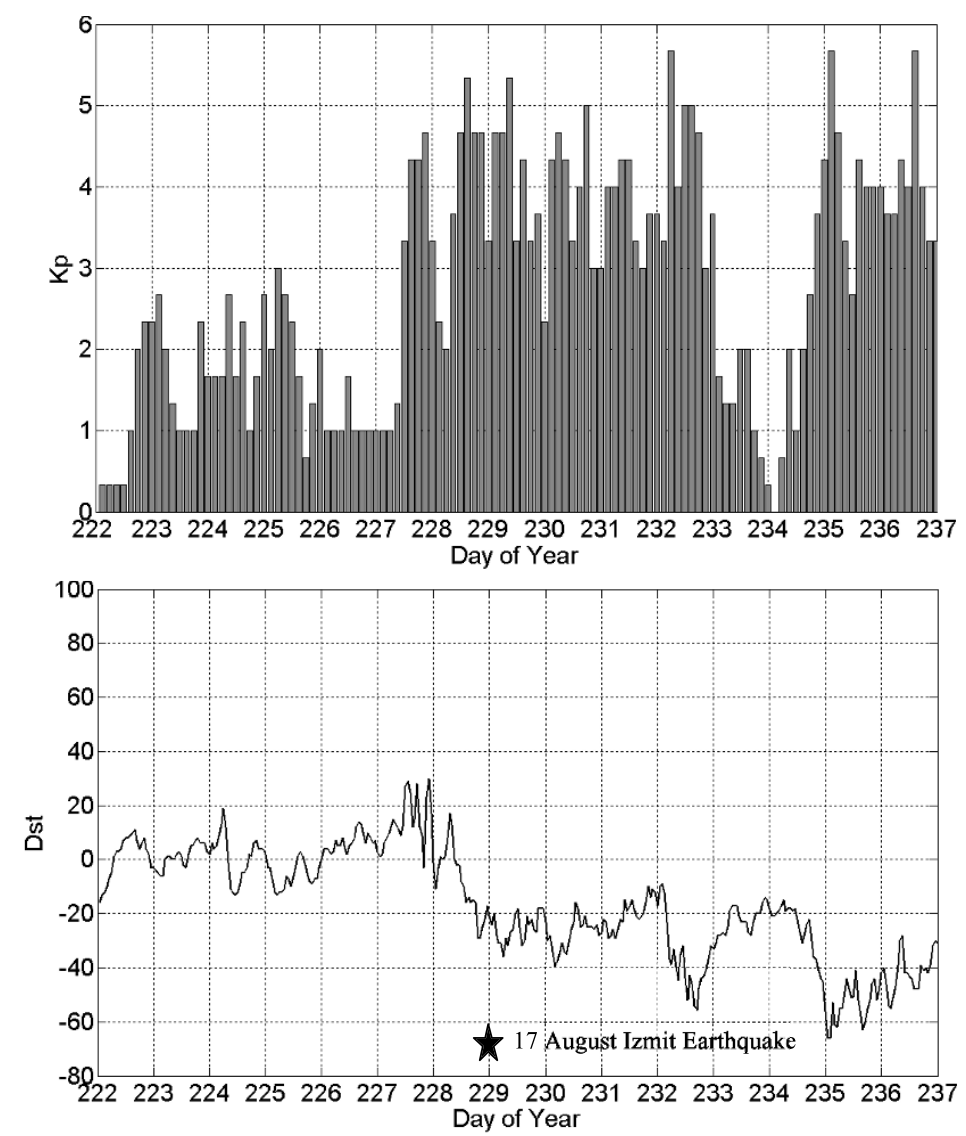

Fig. 3. Geomagnetic condition values from DOY 222 to 237 for $K_{\mathrm{p}}$ and $D_{\mathrm{st}}$.

prior to the earthquake event, significant deviations of the TEC variations were observed at all stations. In order to determine the significance of the VTEC disturbances, we computed new upper and lower bounds $\bar{x} \pm 1.96 \sigma$ with $\bar{x}$ (median of the VTEC values $\approx 20$ TECU) and $\sigma$ (standard deviation $\approx 6.5$ TECU). Days 225 and 227, before the earthquake, have statistically a significant signal with a confidence level of $95 \%$ (Fig. 4).

Figure 4 indicates an anomalous (compared with other days) sudden decrease of the maximum TEC level on day 226, before the earthquake. A similar effect of TEC and $N_{\mathrm{m}} F_{2}$ deviations was considered by Liu et al. (2004) to be a pre-earthquake ionosphere anomaly. Liu et al. (2011) concluded that the temporal TEC variation over the epicenter indicated the pre-seismic anomaly to be a significant enhancement of the ionosphere TEC one day before the 2010 (M 7) Haiti earthquake. Liu et al. (2010) reported that seismo-ionospheric precursors of anomalous decreases in the TEC occurred 5 days prior to an $M 9.3$ earthquake which took place in Sumatra-Andaman, Indonesia on 26 December, 2004. The results indicated that the temporal precursor of the GPS TEC around the epicenter was significantly reduced during the afternoon period 5 days before the earthquake.

The $K_{\mathrm{p}}$ index and the $D_{\text {st }}$ index are stable and quiet on days 225 and 226 before the earthquake, which suggests that the anomalous TEC enhancement around the epicenter 3 days before the earthquake is unlikely to be related to space weather changes and/or magnetic activities. How- ever, it is difficult to confirm that the chance of the anomaly on day 226 not associated with the 17 August, 1999, earthquake. $K_{\mathrm{p}}$ index and $D_{\text {st }}$ index are not stable and quiet on day 227 and later before the earthquake, which suggests that the anomalous TEC enhancement around the epicenter a day before the earthquake is more likely to be related to space weather changes and or magnetic activities.

The TEC deviations are slightly similar in the region near the earthquake epicenter and at the MERT station as the farthest away site. Systematic decreases in the ionospheric TEC during the three days before the earthquake onset were observed at all stations. This result is consistent with those of earlier investigators (e.g. Ondoh, 1998; Plotkin, 2003). Systematic decreases in the ionospheric $F_{2}$-layer critical frequency below its monthly median for 3 days before the 12 July, 1993, earthquake in northern Japan were reported by Ondoh (1998); local geomagnetic activities were quiet or moderate with no geomagnetic storm before the earthquake. Plotkin (2003) observed systematic decreases in ionospheric TEC during the two days before the 13 February, 2001, El Salvador earthquake at a set of stations near the earthquake location and probably in a region of about $1000 \mathrm{~km}$ from epicenter. This result is consistent with our estimation if one takes into account the distance from the epicenter to the MERT station.

Some investigations have shown that ionospheric anomalies are connected with the electric field (Rapoport et al., 2004; Pulinets and Boyarchuk, 2004). The size of the modified area in the ionosphere is of the same order of magni- 
(a)

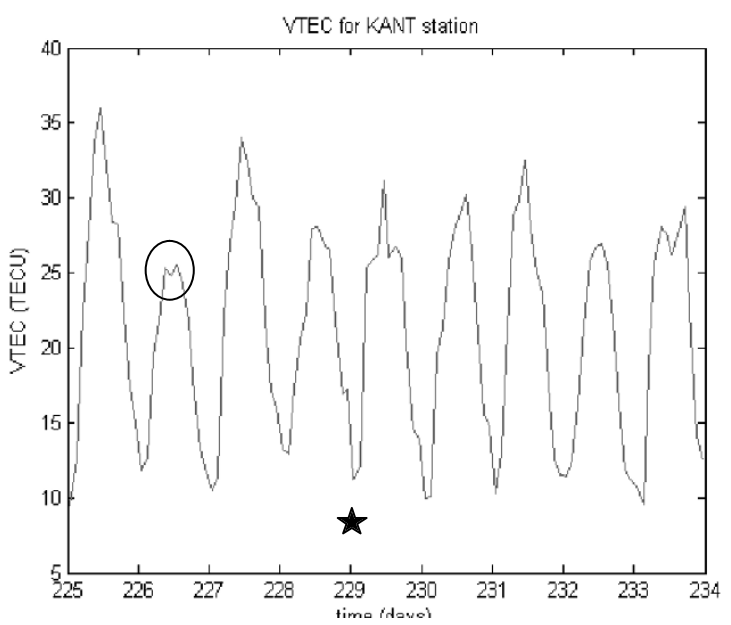

(b)

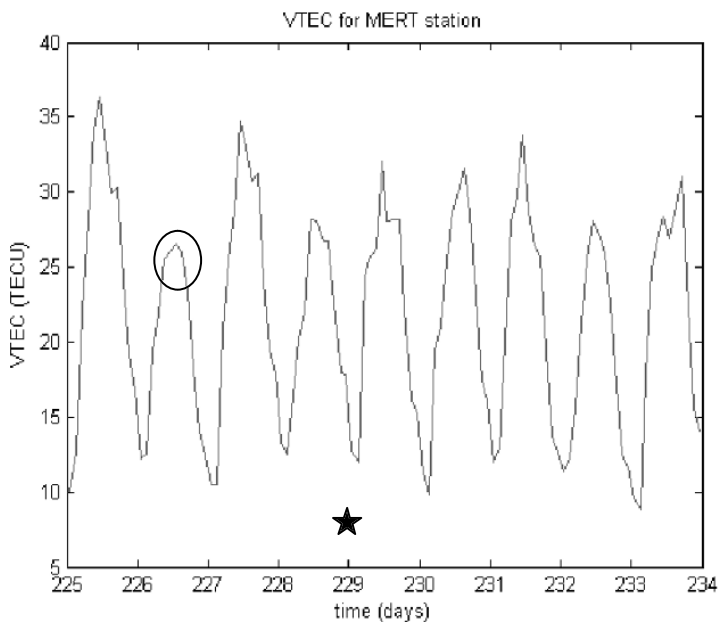

(c)

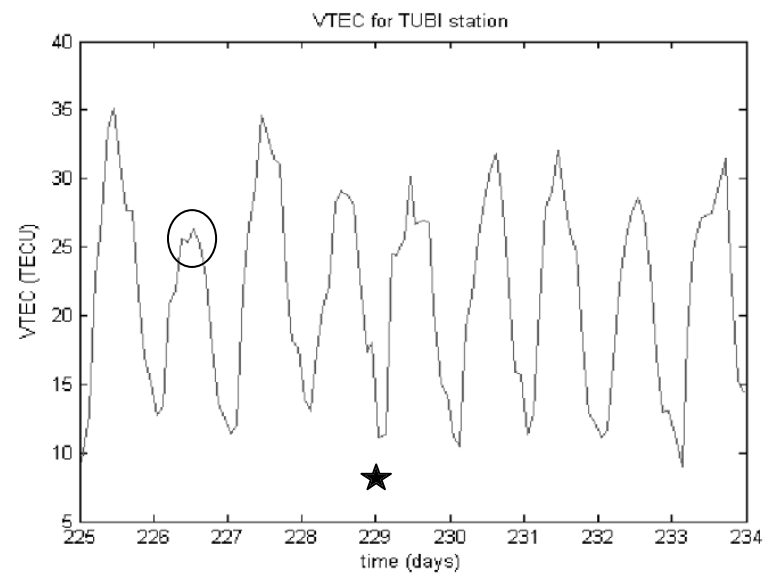

Fig. 4. Vertical TEC observations, as observed from KANT, MERT and TUBI reference stations, during the period 13-22 August, 1999 (days 225-234). The star indicates the time of the earthquake $(00.01 \mathrm{UT})$ and the circle indicates a low anomaly before the earthquake.

tude as the size of the earthquake preparation zone on the ground surface (Dobrovolsky et al., 1979).

We computed $R=1853 \mathrm{~km}$ for the 17 th August, 1999, Izmit earthquake $(M=7.6)$ using the Dobrovolsky formula ( $R=10^{0.43 M}$ ) where $R$ is the radius of the earthquake preparation zone, and $M$ is the earthquake magnitude, and the dimensions of the earthquake preparation zone at the lithosphere were very large. Hence, the occurrence of a large-scale seismo-ionospheric anomaly within a few days before the earthquake is quite well explained, as shown in Fig. 4.
To obtain a more precise view of the spatial distribution in latitude and longitude of the TEC, we computed the slant TEC (STEC) for all the satellite-receiver lines-of-sight for the TUBI station, during the period 13-22 August, 1999 (days 225-234) (Fig. 5). Each curve corresponds to a time sequence of the TEC along a ray path between a satellite and a receiver, and the large variability of the curves is related to differing look angles of the GPS satellites and receiver clock biases, among other factors.

Figure 5(a) indicates that systematic decreases of the ionospheric TEC during the day before the earthquake onset 
(a)
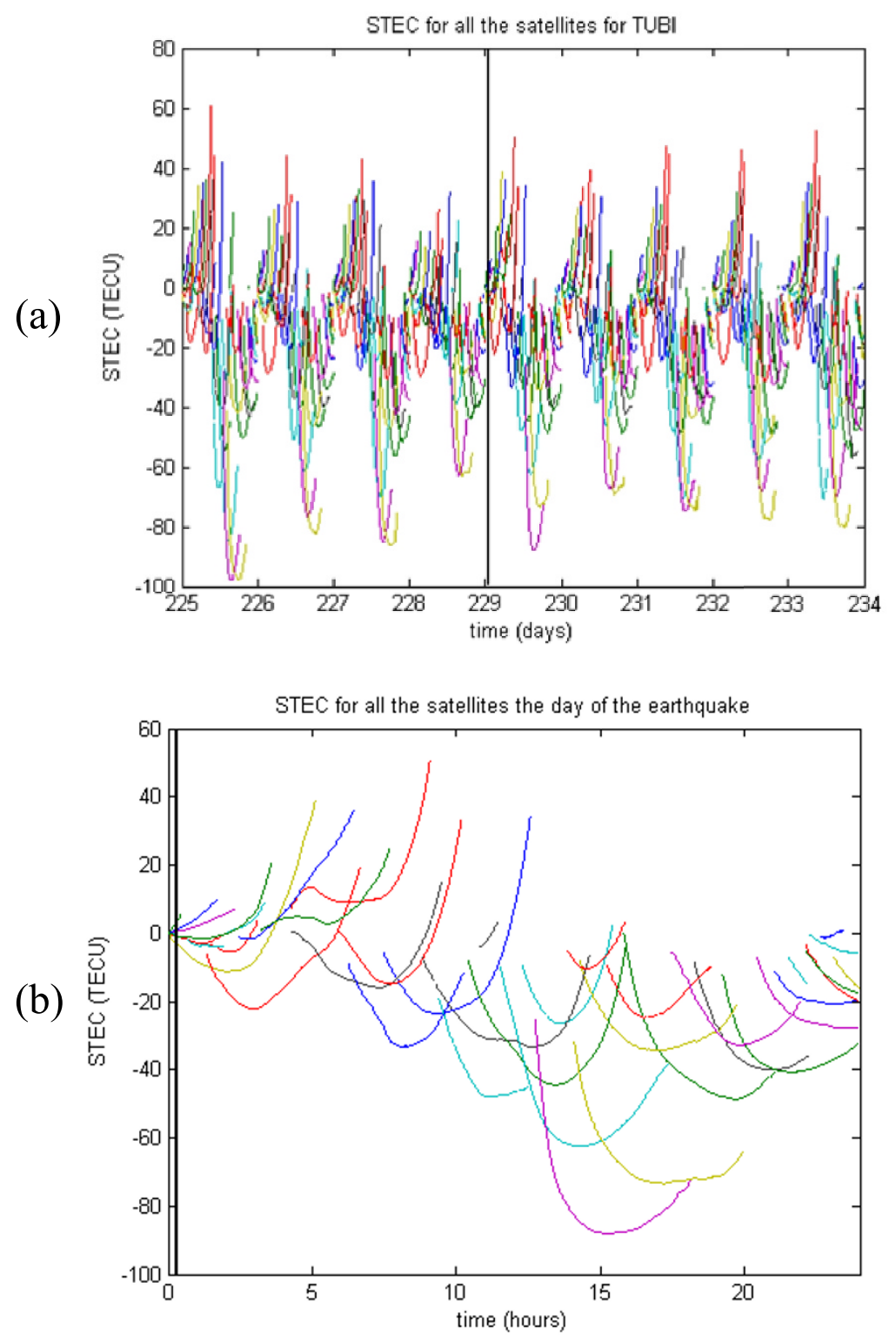

Fig. 5. (a) Temporal variation of the slant TEC (STEC) observed at the TUBI station, during the period 13-22 August, 1999 (days 225-234), (b) STEC for all the satellites the day of the earthquake from the TUBI station. The star indicates the time of the earthquake.

were observed at the TUBI station during the period 13-22 August, 1999 (days 225-234). Figure 5(b) shows more details about STEC for the day of the earthquake at the TUBI station. The lower anomalies can be found during the day prior to the earthquake, while the upper anomalies can be found on the earthquake day. This result is consistent with that of earlier investigators (e.g., Ondoh, 1998; Pulinets, 1998; Plotkin, 2003; DasGupta et al., 2006). The $K_{\mathrm{p}}$ index and the $D_{\text {st }}$ index are not stable and quiet on day 228 before the earthquake, which suggests that the anomalous TEC enhancement around the epicenter a day before the earthquake is more likely related to space weather changes and or magnetic activities.

The rate of the TEC has been obtained every epoch (30 second) for 2 hours before, and after, the earthquake to monitor the stochastic behavior of the TEC (Fig. 6). Therefore, the TEC data derived from four satellites PRN05, PRN06, PRN08 and PRN30 for the TUBI, MERT and
KANT stations, during 2 hours before, and after, the earthquake, was used. As shown in Fig. 6, the rates of the TEC values are slightly similar in the region near the earthquake epicenter, and the anomalous behavior of the TEC variations of every epoch from satellite PRN 6 is clearly seen one hour (23 UT) before the earthquake at the TUBI station located near the earthquake epicenter. This result is consistent with that of earlier investigators (e.g., Afraimovich et al., 2001; Smirova and Smirnow, 2005).

Afraimovich et al. (2001) investigated the form and dynamics of shock-acoustic waves (SAW) generated by the 17 August, 1999, Izmit earthquake. The results were obtained from analyzing the ionospheric effect of the SAW during the earthquake for PRN 6. The delay of the SAW response is $20 \mathrm{~min}$ (day 229). The SAW has the form of an $N$-wave with a period $T$ of about $390 \mathrm{~s}$ and an amplitude $A_{I}=0.12$ TECU, which is an order of magnitude larger than the TEC fluctuations for background days (day 228, 230). 

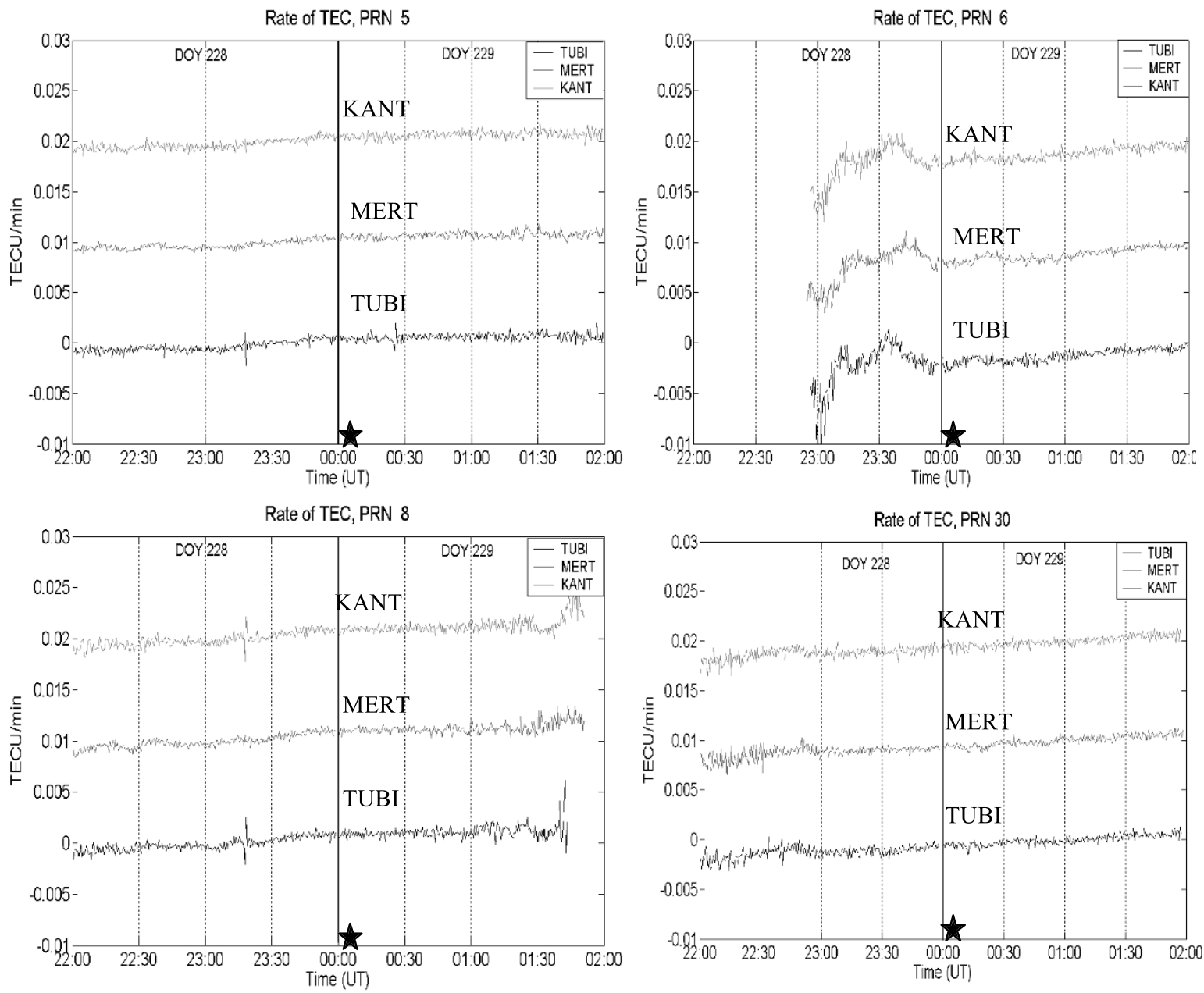

Fig. 6. Rate of TEC values for PRN5, 6, 8, 30 at the TUBI, MERT, and KANT stations every epoch, and the star indicates the time of the earthquake.

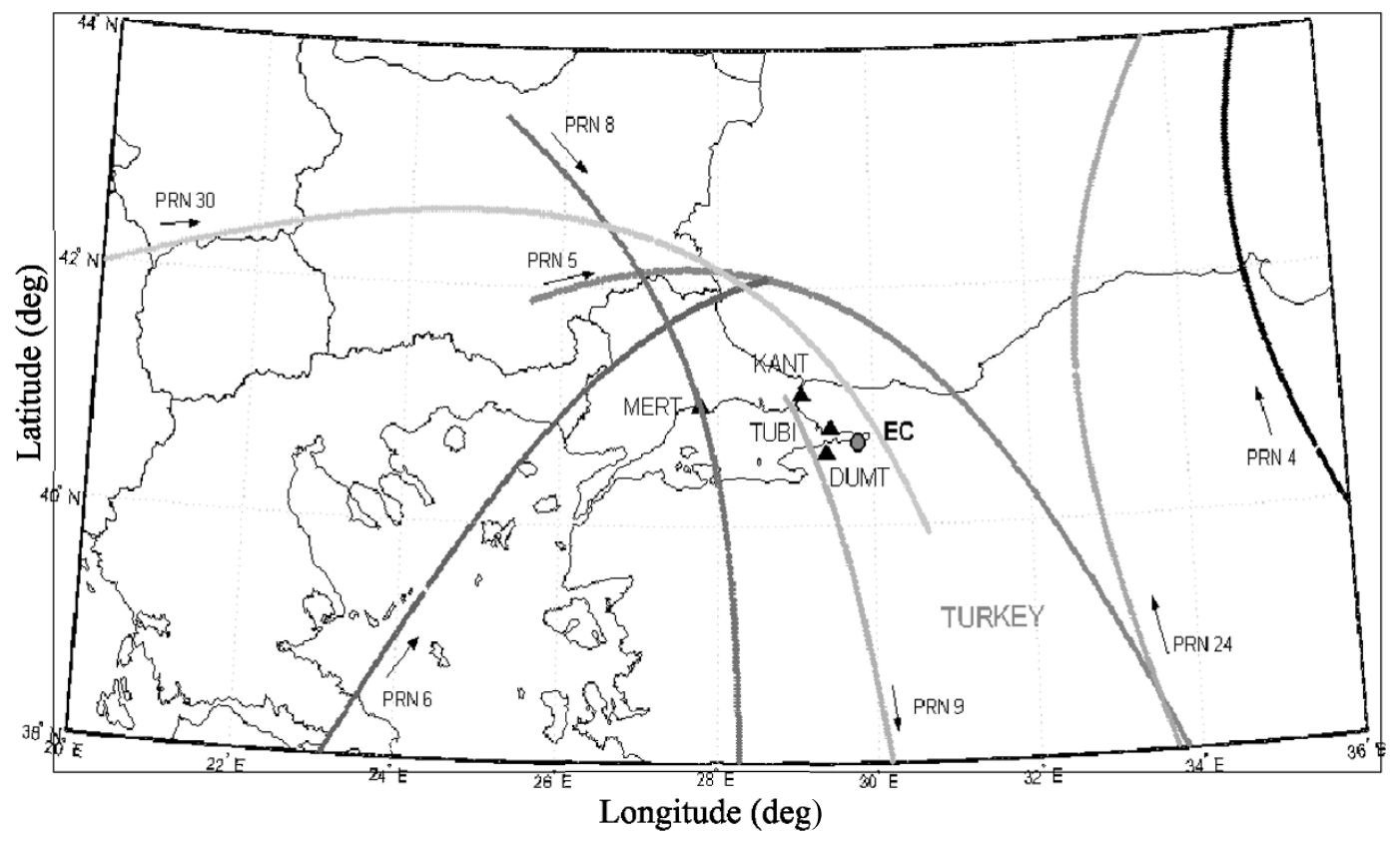

Fig. 7. Line of sight ionospheric pierce points of the satellites. 
Smirova and Smirnow (2005) carried out an ionosphere state analysis during August 13-18, 1999, and considered the electronic concentration pro le and its maximal meaning in the $F_{2}$-layer. The temporary variations in the electronic plasma maximum were obtained by the ANKR station located $317 \mathrm{~km}$ away from the epicenter. There was obviously no explicit modi cation of the ionosphere, and August 16 (day 228) indicated only the temporary character of electronic density values remaining the same. They proposed that it was necessary to conduct processing and data analysis for those areas having a high density of GPS receiver locations.

Figure 7 shows corresponding tracks of the satellitereceiver lines of sight in the ionosphere shell, where most of the TEC contributing to the range delay is concentrated. The rotational period of the GPS satellites is approximately $12 \mathrm{~h}$, such that the satellite-receiver line of sight moves through various regions of the ionosphere over time (Skone and Cannon, 1999).

\section{Discussion and Conclusion}

We have studied the response of the ionosphere to the large earthquake that occurred in Izmit, Turkey, on August 17, 1999, using GPS data obtained from MAGNET. The observational results indicated that anomalous variations of the TEC, derived from GPS observations, were detected during the three days before the Izmit earthquake. The TEC anomaly decreased with an enhancement of about 810 TECU relative to the non-distributed state of the ionosphere. Negative TEC disturbances (TEC decreases) have also been observed for several Taiwan and Sumatra earthquakes (Liu et al., 2004, 2006). Liu et al. (2004) further examined the GPS TEC during all of the $20 M \geq 6$ earthquakes in the Taiwan area from September 1999 to December 2002. They found that anomalous decreases in the GPS TEC often appeared 1-5 days before the earthquakes. These effects were probably related to the equatorward displacement of the equatorial northern crest and the reduction of the electron concentration in the crest.

In addition, the short term displacement rates have been estimated for the GPS stations in the region. The results showed that the TUBI station located to near the epicenter of the earthquake has much bigger relative coseismic deformations than the other stations, but all the stations show signi cant relative coseismic deformations.

Many scientists have investigated ionospheric anomalies prior to earthquakes with the help of statistical analysis of typical seismic events (Liu et al., 2001, 2009; Pulinets et al., 2003). Some studies have been made using a stochastic test on the statistical analysis of the GPS TEC temporal and spatial variations, and the reliability of seismic-ionospheric anomalies has been improved (Liu et al., 2010; Xia et al., 2011). Liu et al. (2010) indicated that, to identify seismoionospheric precursors, both temporal and spatial statistical analyses were required, and results have con rmed that the seismo-electromagnetic environment changed and that ionospheric conjugate effects play important roles. Xia et al. (2011) reported that most earthquakes have shown signi cant abnormalities having similar characteristics. The results also showed that ionosphere anomalies were more dependent on the focal depths of earthquakes than their magnitudes.

It is well known that the VTEC and the frequency of the $F_{2}$-layer $\left(f_{\mathrm{o}} F_{2}\right.$ or $\left.N_{\mathrm{m}} F_{2}\right)$ are two different physical quantities. It is noted that the $N_{\mathrm{m}} F_{2}$ is the electron density at the $F_{2}$-peak, about $300-500-\mathrm{km}$ altitude, while VTEC is the integration from a ground-based receiver to the GPS satellite orbit at about 20,200 km altitude (Liu et al., 2004). Liu et al. (2001) showed that two measurements of $N_{\mathrm{m}} F_{2}$ and GPS TEC had similar tendencies and were highly correlated. Hence, the GPS TEC can be employed to detect seismoionosphere signatures. Liu et al. (2004) also proposed that the TEC anomalies initialized near the Earth's surface, then extended upward to a higher altitude. The anomalous reductions of electron densities may be attributed to the seismoelectromagnetic signals that topically affect the ionospheric plasma (Liu et al., 2009). Liu et al. (2009) showed that the eastward plasma $E \times B$ drift may result in the abnormal enhancement of TEC slightly shifting to the east of the epicenter.

In conclusion, the continuous GPS networks, based on TEC monitoring, provide a valuable tool for the permanent monitoring of the ionosphere not only on a global scale, but also on a regional scale of the world and may contribute to earthquake forecasting. However, some research needs to be done without the selective availability (SA) on, and with a lower activity due to the sun and with a higher sample rate (maybe per second) in order to obtain reliable results for the prediction of earthquakes. The GPS data analyzed in this study may be helpful to further studies trying to identify earthquake precursors from ionospheric anomalies obtained from GPS stations. It is hoped that it will contribute to monitoring studies to identify any pre-earthquake signal, together with other classical techniques, which already run in the region.

Acknowledgments. The authors thank the reviewers for their assistance in evaluating this paper.

\section{References}

Afraimovich, E. L. and E. I. Asta eva, TEC anomalies-Local TEC changes prior to earthquakes or TEC response to solar and geomagnetic activity changes?, Earth Planets Space, 60, 961-966, 2008.

Afraimovich, E. L., N. P. Perevalova, A. V. Plotnikov, and A. M. Uralov, The shock-acoustic waves generated by earthquakes, Ann. Geophys., 19, 395-409, 2001.

Afraimovich, E. L., E. I. Asta eva, M. B. Gokhberg, V. M. Lapshin, V. E. Permyakova, G. M. Steblov, and S. L. Shalimov, Variations of the total electron content in the ionosphere from GPS data recorded during the Hector Mine earthquake of October 16, 1999, California, Russian J. Earth Sci., 6(5), 339-354, 2004.

DasGupta, A., A. Das, D. Hui, K. K. Bandyopadhyay, and M. R. Sivaraman, Ionospheric perturbations observed by the GPS following the December 26th, 2004 Sumatra-Andaman earthquake, Earth Planets Space, 58, 167-172, 2006.

Dautermann, T., E. Calais, J. Haase, and J. Garrison, Investigation of ionospheric electron content variations before earthquakes in southern California, J. Geophys. Res., 112, B02106, doi:10.1029/2006JB004447, 2007.

Davies, E. and D. M. Baker, Ionospheric effects observed around the time of the Alaskan earthquake of March 28 1964, J. Geophys. Res., 70, 2251-2253, 1965.

Dobrovolsky, I. R., S. I. Zubkov, and V. I. Myachkin, Estimation of the size of earthquake preparation zones, Pure Appl. Geophys., 117, 1025-1044, 1979. 
Dogan, U., S. Ergintav, H. Demirel, R. Çakmak, and H. Özener, Estimation of the time-dependent crustal movements of the Izmit earthquake, $J$. Geodyn., 36, 615-632, 2003.

Ergintav, S., R. Bürgmann, S. McClusky, R. Cakmak, R. E. Reilinger, O. Lenk, A. Barka, and O. Gurkan, Postseismic deformation near the Izmit earthquake 17 August, 1999, Bull. Seismol. Soc. Am., 92, 194 207,2002

Hugentobler, U., S. Schaer, and P. Fridez, Bernese GPS Software Version 4.2, 515 pp., Astronomical Institute, University of Berne, 2001.

Krankowski, A., I. E. Zakharenkova, and I. I. Shagimuratov, Response of the ionosphere to the Baltic Sea earthquake of 21 September 2004, Acta Geophys., 54(1), 90-101, 2006.

Le, H., J. Y. Liu, and L. Liu, A statistical analysis of ionospheric anomalies before 736 M6.0+ earthquakes during 2002-2010, J. Geophys. Res., 116, A02303, 2011.

Liu, J. Y., Y. I. Chen, Y. J. Chuo, and H. F. Tsai, Variations of ionospheric total electron content during the Chi-Chi earthquake, Geophys. Res. Lett., 28, 1383-1386, 2001.

Liu, J. Y., Y. J. Chuo, S. J. Shan, Y. B. Tsai, Y. I. Chen, S. A. Pulinets, and S. B. Yu, Pre-earthquake ionospheric anomalies registered by continuous GPS TEC measurements, Ann. Geophys., 22, 1585-1593, 2004.

Liu, J. Y., Y. I. Chen, Y. J. Chuo, and C. S. Chen, A statistical investigation of pre-earthquake ionospheric anomaly, J. Geophys. Res., 111, A05304, 2006.

Liu, J. Y., Y. I. Chen, C. Y. Liu, M. Chen, J. Z. Nishihashi, Y. Q. Li, K. Xia, I. Oyama, K. Hattori, and C. H. Lin, Seismo-ionospheric GPS total electron content anomalies observed before the 12 May $2008 \mathrm{Mw} 7.9$ Wenchuan earthquake, J. Geophys. Res., 114, A04320, 2009.

Liu, J. Y., Y. I. Chen, C. H. Chen, and K. Hattori, Temporal and spatial precursors in the ionospheric Global Positioning System (GPS) total electron content observed before the 26 December 2004 M9.3 SumatraAndaman Earthquake, J. Geophys. Res., 115, A09312, 2010.

Liu, J. Y., H. Le, Y. I. Chen, C. H. Chen, L. Liu, W. Wan, Y. Z. Su, Y. Y. Sun, C. H. Lin, and M. Q. Chen, Observations and simulations of seismo-ionospheric GPS total electron content anomalies before the 12 January 2010 M7 Haiti earthquake, J. Geophys. Res., 116, A04302, 2011.

Ondoh, T., Ionospheric disturbances associated with great earthquake of Hokkaido southwest coast, Japan of 12 July 1993, Phys. Earth Planet. Inter., 105, 261-269, 1998.

Plotkin, V. V., GPS detection of ionospheric perturbation before the 13 February 2001, El Salvador earthquake, Nat. Haz. Earth Syst. Sci., 3,
249-253, 2003.

Pulinets, S. A., Seismic activity as a source of the ionospheric variability, Adv. Space Res., 22, 903-906, 1998.

Pulinets, S. A. and K. Boyarchuk, Ionospheric Precursors of Earthquakes, Springer-Verlag Publ., ISBN 3540208399, Berlin Heidelberg, Germany, 2004.

Pulinets, S. A., A. D. Leganka, T. B. Gaivoronskaya, and V. Kh. Depuev, Main phenomenological features of ionospheric precursors of strong earthquakes, J. Atmos. Sol.-Terr. Phys., 65, 1337-1347, 2003.

Pulinets, S. A., T. B. Gaivoronskaya, and L. Ciraolo, Correlation analysis technique revealing ionospheric precursors of earthquakes, Nat. Haz. Earth Syst. Sci., 4, 697-702, 2004.

Rapoport, Y., V. Grimalsky, M. Hayakawa, V. Ivchenko, D. Juarez-R, S. Koshevaya, and O. Gotynyan, Change of ionospheric plasma parameters under the in uence of electric eld which has lithospheric origin and due to radon emanation, Phys. Chem. Earth, 29, 579-587, 2004.

Saroso, S., J. Y. Liu, K. Hattori, and C. H. Chen, Ionospheric GPS TEC anomalies and $M_{w} 5.9$ earthquakes in Indonesia during 1993-2002, Terr. Atmos. Ocean. Sci., 19(5), 481-488, 2008.

Skone, S. H., The impact of magnetic storms on GPS receiver performance, J. Geod., 75, 457-468, 2001.

Skone, S. H., TECANALYS Operating Manual, Dept. of Geomatics Engineering, Univ. of Calgary, May, 2006.

Skone, S. H. and M. E. Cannon, Ionospheric effects on differential GPS applications during auroral substorm activity, ISPRS Journal of Photo. \& Remote Sensing, 54, 279-288, 1999.

Smirnova, E. V. and V. M. Smirnow, Modi cation of electron density pro le about the earthquake epicenter by GPS data, Recent Advances in Space Technologies, Proceedings of 2nd International Conference on 9-11 June, 2005.

Xia, C., S. Yang, G. Xu, B. Zhao, and T. Yu, Ionospheric anomalies observed by GPS TEC prior to the Qinghai-Tibet region earthquakes, Terr. Atmos. Ocean. Sci., 22(2), 177-185, 2011.

Zakharenkova, I. E., I. I. Shagimuratov, A. Krankowski, and A. F. Lagovsky, Precursory phenomena observed in the total electron content measurements before Great Hokkaido earthquake of September 25, 2003 ( $M=8.3)$, Stud. Geophys. Geod., 51, 267-278, 2007.

U. Dogan (e-mail: dogan@yildiz.edu.tr), S. Ergintav, S. Skone, N. Arslan, and D. Oz 